\title{
Induction healing of concrete reinforced by bitumen-coated steel fibres
}

\author{
Claudia Romero Rodríguez ${ }^{1,2,}$,, Stefan Chaves Figueiredo ${ }_{2}^{2}$, Bernardino Chiaia ${ }^{1}$, Erik \\ Schlangen \\ ${ }^{1}$ Politecnico di Torino \\ Turin, Italy \\ e-mail: claudia.romerorodriguez@studenti.polito.it \\ bernardino.chiaia@polito.it \\ 2 \\ Delft University of Technology \\ Delft, Netherlands \\ e-mail: S.ChavesFigueiredo@tudelft.nl \\ Erik.Schlangen@tudelft.nl
}

Key words: self-healing; shrinkage cracking; SFRC; induction heating; bitumen.

\begin{abstract}
Cracking in concrete structures compromises the durability and functionality of the structures themselves. Different kinds of self-healing concretes, less or more sophisticated, have been developed in the past ten years to overcome early cracks in structures. An experimental study of a novel self-healing concrete is presented. Bitumen, used as the healing agent, is introduced in fresh fibre-reinforced concrete as the coating of steel fibres. The mechanism exploits induction energy to heat up the steel fibres inside the cracked concrete matrix; the bitumen then melts and finally flows into the cracks, sealing them. The aim of the research is to set up the main parameter affecting the performance of the healing mechanism as well as its efficiency. In order to achieve this goal, the microstructure of healed specimens has been studied through Light Microscope. Mechanical behaviour and permeability of the samples, before and after healing, were also checked. Fiber content is studied in the paper amongst the many parameters affecting the mechanism. Results point out the potential of the proposed self-healing mechanism to contrast early cracking (i.e. due to shrinkage). Presence of a certain amount of fibres bridging the crack highly influenced the healing efficiency, and so a uniform distribution inside the concrete matrix, which was directly related to fibre amount and its optimum concrete matrix.
\end{abstract}

\section{INTRODUCTION}

Concrete is the most widely used man made construction material [1]. Its physical characteristics during the fresh state allow the creation of form-variegated elements like beams, shells, columns, etc.; while after hardening and setting develops high compressive strength and stability. On the other hand, the heterogeneity of concrete leads to the presence of an elevated number of defects which result on low tensile strength of concrete[2]. Concrete is subjected to tensile loads during life due to shrinkage, creep and thermal and mechanical loads which cause cracking, even at early stages. Cracks are detrimental to the durability of concrete; in fact, deleterious substances can penetrate easily inside concrete through them, where either react with cement paste or corrode reinforcements. Repairing concrete structures is not only expensive but also leads to undesirable interruption of service life, causing discomfort 
to users $[3,4]$.

Development of a new material which requires faint human intervention to seal cracks is hereby described. Bitumen, used as the healing agent, is introduced in fresh fibrereinforced concrete as the coating of steel fibres. The mechanism exploits induction energy to heat up the steel fibres [5] inside the cracked concrete matrix; the bitumen then melts and finally flows into the cracks, sealing them.

Specifically, this paper deals with the analysis of one parameter affecting the performance of the healing mechanism and of the material itself: fiber content. In order to do so, fluorescent microscopy was used to quantify crack filling, water leakage rates of the crack before and after healing were measured and mechanical behavior of healed and unhealed specimens was assessed.

\section{MATERIAL AND SAMPLE PREPARATION}

\subsection{Preparation of bitumen-coated steel fibers}

HE++75/50 hooked-end steel fibres from Arcelor Mittal with length $50 \mathrm{~mm}$ and diameter $0.75 \mathrm{~mm}$ were used to prepare the coated fibres. Dimensions of these fibres made feasible the coating process with respect to shorter fibres.

The steel fibres were embedded within one hooked extremity $(10 \mathrm{~mm})$ in cork slabs. Kuwait $40 / 60$ penetration class bitumen was heated in the oven at $160^{\circ} \mathrm{C}$ for 2 hours and poured into a basin inside which the slabs were sank and then hanged till bitumen got cold. The process can be seen in Figure 1.

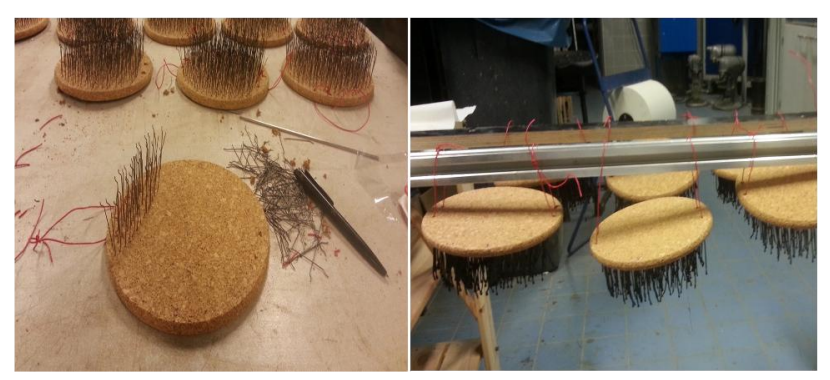

Figure 1: Bitumen coating of steel fibres.

Manual chopping of the coated fibres was implemented to achieve the desired length of the fibres: $\mathrm{L}=20 \mathrm{~mm}$ and to eliminate the non-coated extremities. Length of the fibres was the result of a compromise between the time consumption of the labour and the dimensions of the specimens.

\subsection{Concrete samples preparation}

Massive prismatic beams, with dimensions shown in Figure 2a were used as specimens for microscopy and mechanical tests of healed specimens; while a hole along the length of the prisms was produced to perform permeability testing (Figure 2b) by introducing a smooth steel bar during the casting and pulling it out after 24 hours.
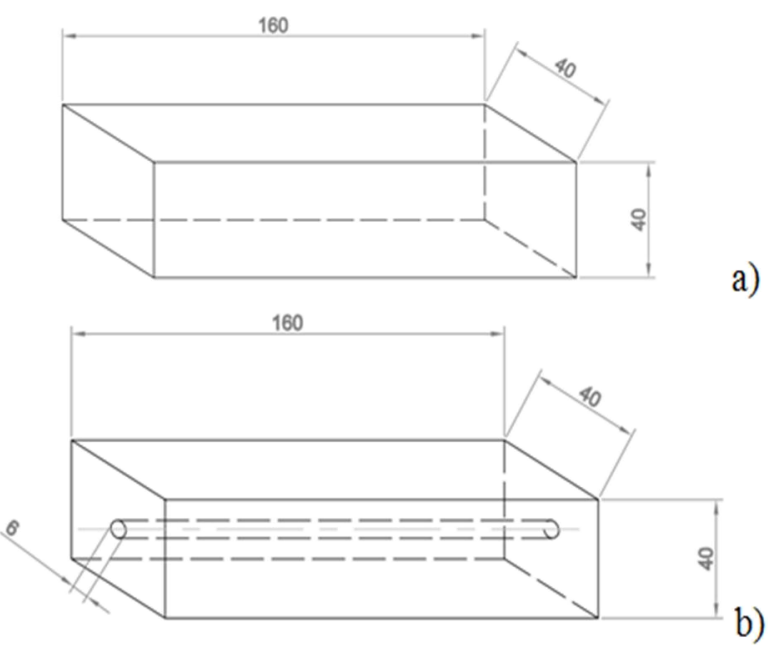

a)

Figure 2: Geometry and dimensions of specimens a) for microscopy and mechanical testing, b) for permeability testing.

The concrete mixtures were prepared by using CEM I 42,5N from ENCI (Netherlands), classes of aggregates $4-8 \mathrm{~mm}, 2-4 \mathrm{~mm}, 1-2 \mathrm{~mm}$, $0.5-1 \mathrm{~mm}, \quad 0.250-0.5 \mathrm{~mm}$ and $0.125-0.250 \mathrm{~mm}$, graded according to the maximum and minimum limit curves prescribed for FRC [6] and MasterGlenium ${ }^{\circledR}$ 51, superplasticizer admixture within the range of 0.8 and $0.85 \%$ in mass of cement.

Three different mixes were prepared by using three contents of bitumen-coated steel fibres: $1.0 \%, 1.5 \%$ and $2.0 \%$ in volume of concrete. Table 1 shows the mixtures used in the experiments. 


\begin{tabular}{|c|c|c|c|c|}
\hline \multicolumn{2}{|c|}{ Components } & $\begin{array}{l}\text { b1 } \\
\text { fcon2 }\end{array}$ & $\begin{array}{l}\mathrm{b} 2 \\
\text { fcon2 }\end{array}$ & $\begin{array}{l}\mathrm{b3} \\
\text { fcon2 }\end{array}$ \\
\hline \multicolumn{2}{|c|}{ Cement $\left[\mathrm{kg} / \mathrm{m}^{3}\right]$} & 467 & 467 & 467 \\
\hline \multicolumn{2}{|c|}{ Water $\left[\mathrm{kg} / \mathrm{m}^{3}\right]$} & 210 & 210 & 210 \\
\hline \multicolumn{2}{|c|}{ Coated fibers $\left[\mathrm{kg} / \mathrm{m}^{3}\right]$} & 79 & 119 & 158 \\
\hline \multicolumn{2}{|c|}{ Sp [\% in mass of cement] } & 0.8 & 0.83 & 0.84 \\
\hline \multirow{6}{*}{$\begin{array}{c}\text { Aggrega } \\
\text { tes } \\
{\left[\mathrm{kg} / \mathrm{m}^{3}\right]}\end{array}$} & $4-8 \mathrm{~mm}$ & 459 & 456 & 452 \\
\hline & $2-4 \mathrm{~mm}$ & 328 & 325 & 323 \\
\hline & $1-2 \mathrm{~mm}$ & 246 & 244 & 242 \\
\hline & $0.5-1 \mathrm{~mm}$ & 197 & 195 & 193 \\
\hline & $0.25-0.5 \mathrm{~mm}$ & 246 & 244 & 242 \\
\hline & $0.125-0,25 \mathrm{~mm}$ & 164 & 162 & 161 \\
\hline
\end{tabular}

Table 1: Mix design of concrete samples.

\section{EXPERIMENTAL METHODS}

\subsection{Crack generation}

The specimens were cracked through 3-Point bending test, using an Instron ${ }^{\circledR} 8872$ by controlling the crack width, taken as the average between two LVDTs disposed horizontally at the bottom of the sides. The test was stopped when crack width reached $w=200 \mu \mathrm{m}$, whereupon the beams were unloaded and elastic deformation was recovered to obtain a final crack width of $w=160 \mu \mathrm{m}$ in average.

\subsection{Induction heating}

Immediately after the introduction of cracking, the specimens were subjected to the healing intervention. An induction heating generator from HÜTTINGER Electronic Germany was used to heat the fibers inside the specimens; the cracked bottom was placed at $10 \mathrm{~mm}$ from the coil. Frequency of the magnetic field was fixed at $70 \mathrm{kHz}$ and the capacity of the generator was $50 \mathrm{~kW}$. Such parameters have a tremendous influence on the heating rates [7], but they weren't studied within this research.

A full colour infrared camera FLIR, Type A320, was used to record temperature distribution on the samples surface (Figure 3). ThermaCAM $^{\mathrm{TM}}$ Researcher Pro 2.10 was used for the treatment, processing and analysis of the recorded images.

\subsection{Fluorescent microscopy}

In order to investigate the presence of bitumen filling the cracks, fluorescent microscopy was ideal to perform due to the contrast between dye, concrete matrix and bitumen.

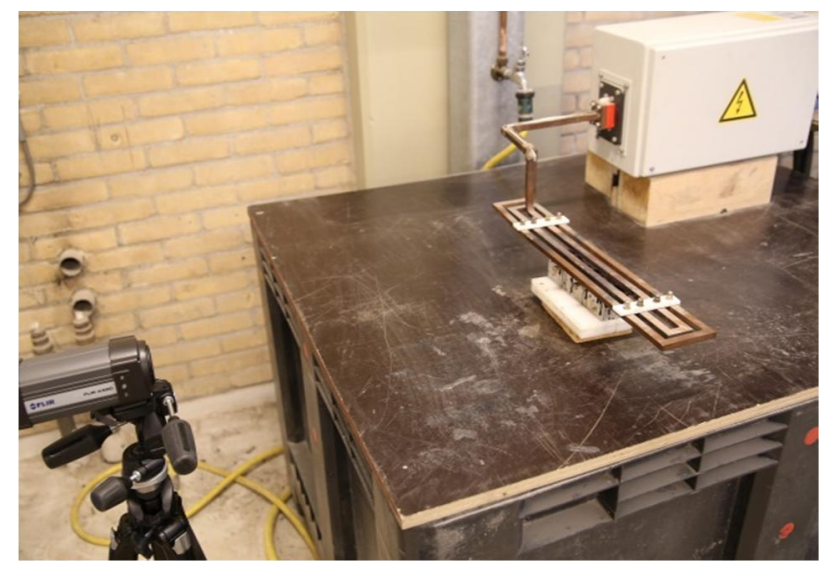

Figure 3: Set-up of induction heating and infrared camera measurements.

Seven days old prisms from b1fcon1, b2fcon 2 and b3fcon 2 mixtures were cracked, healed and impregnated with a yellow-dyed epoxy resin. Four longitudinal sections were sawn from each specimen as described in Figure 4 and a second impregnation was performed on them. Silicon carbide paper was used to grind and polish the sections with aid of a polishing machine.

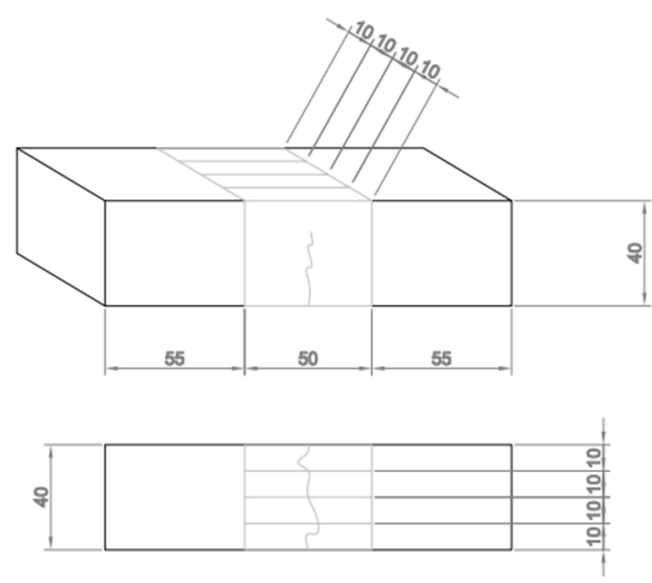

Figure 4: Longitudinal sections obtained from healed specimens.

Leica Light Microscope and UV filter were used to observe the single cracked sections. The images obtained from each section were assembled in one and the total area of the crack and the bitumen-filled area of it measured with AutoCAD ${ }^{R} 2014$. 
The crack filling efficiency (C.F.E) was defined as:

$$
\text { C. F. E. }[\%]=\frac{A_{\text {filled } \text { crack }}}{A_{\text {total crack }}}
$$

\subsection{Permeability test}

Permeability test via water flow which setup is shown in Figure 5 was used to verify the recovery on the crack water leakage rates after healing of 28 days old holed prismatic specimens.

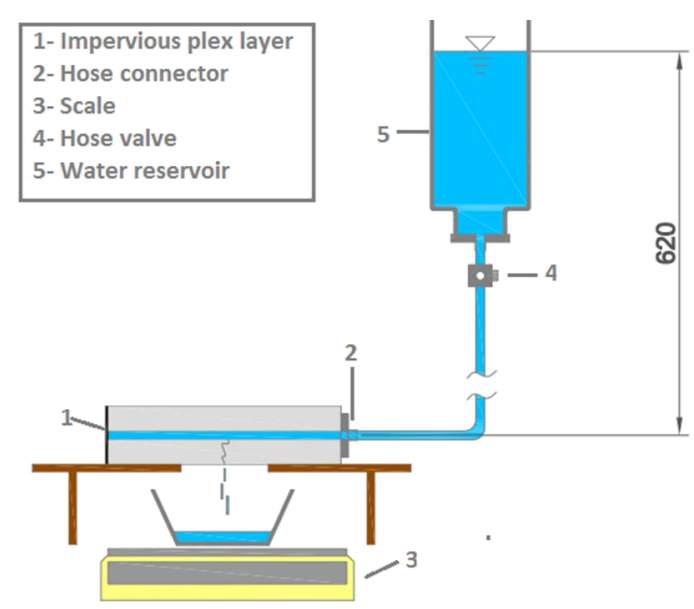

Figure 5: Permeability test via water flow [8].

A hose was connected to one extremity of the longitudinal hole of the beam by means of a connector, while the other extremity was sealed with a plex layer to prevent the water from going out through it. The valve was opened and water started to flow inside the previously saturated specimens. Since the only escape path was the crack crossing the hole, water started leaking from it and the weight of water was measured as a function of time. The water head was kept constant at $0.62 \mathrm{~m}$, offering a water pressure in the hole of $\mathrm{p}=0.061 \mathrm{bar}$.

The test was performed before and after healing and the healing efficiency (H.E.) was calculated as follows:

$$
\text { H. E. }[\%]=\frac{w_{\text {unhealed }}(\mathrm{t})-\mathrm{w}_{\text {healed }}(\mathrm{t})}{\mathrm{w}_{\text {unhealed }}(\mathrm{t})} * 100
$$

Where:

$w_{\text {unhealed }}(t)$ is the weight of the water leaked at the time " $t$ " of the unhealed specimen; $w_{\text {healed }}(t)$ is the weight of the water leaked at the time " $t$ " of the healed specimen.

\section{RESULTS AND DISCUSSION}

\subsection{Heating speed and fibres distribution}

The average temperature of the line L01 near to the cracked bottom side of the beams (upside down in Figure 6) was measured during heating.

If the fibres distribution is not uniform, the heating speed won't be constant along the line, as it can be observed in Figure 6. A uniform horizontal distribution of temperature should be expected because the distance from the coil to the line along which the measurement was made, remains constant and so the intensity of the alternating magnetic field. Each fibre develops Joule's heat in direct proportion to it [7] but since the conductive filler is dispersed within the concrete matrix, the heat transfer from fibres towards concrete surface depends upon the fibres concentration near to it.

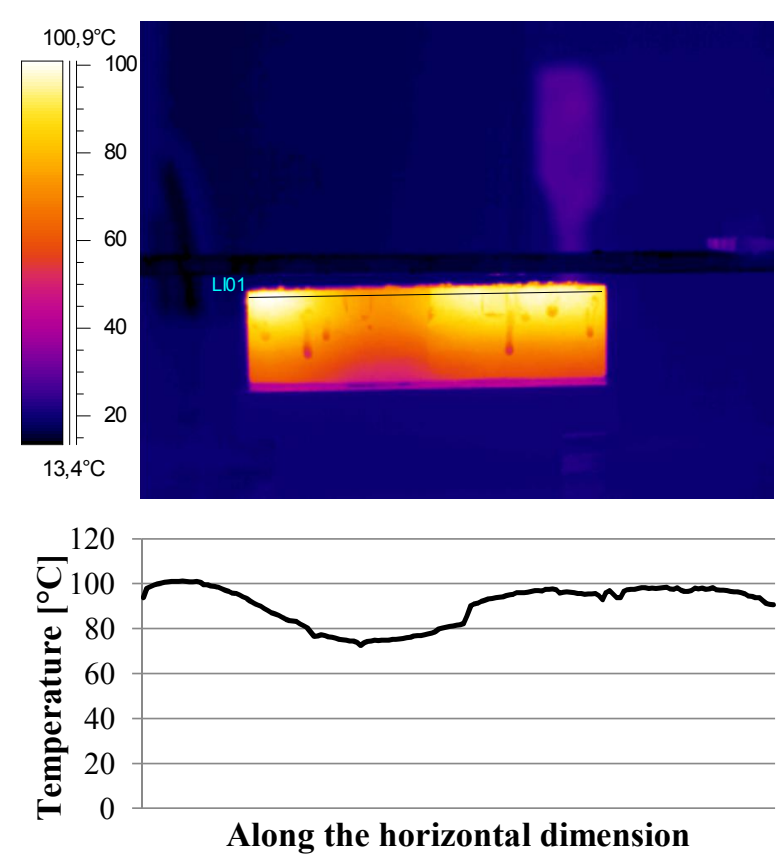

Figure 6: Thermal image of a b3fcon 2 specimen after induction heating.

As expected, the temperature values went from higher to lower along the vertical dimension as a consequence of the increasing distance from the coil. 


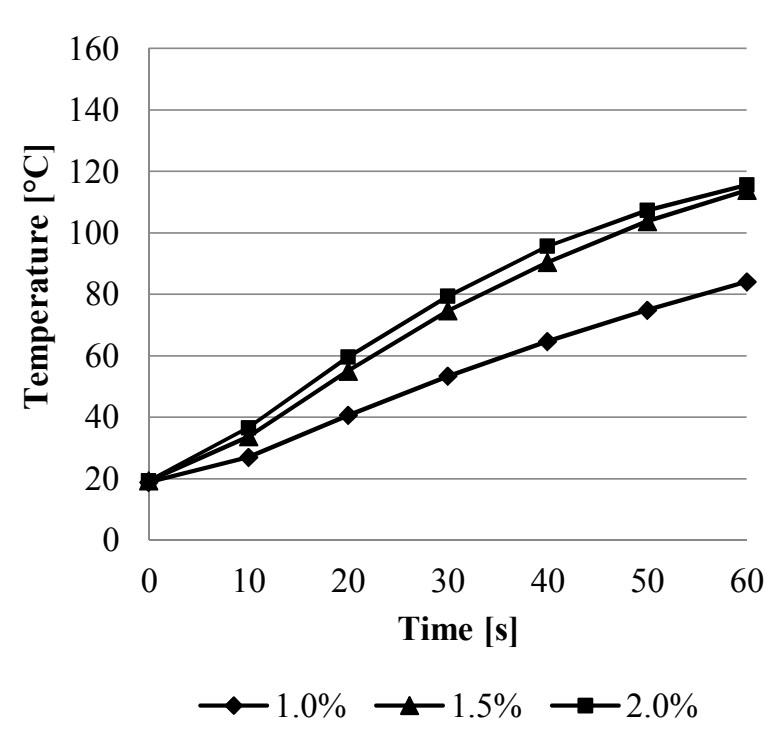

Figure 7: Average temperature of L01 vs. time during heating of concrete beams with different fibre contents.

The graph in Figure 7 shows the average temperature of L01 during heating for b1fcon2, $\mathrm{b} 2 \mathrm{fcon} 2$ and $\mathrm{b} 3 f \mathrm{fcon} 2$. The higher the fibre content, the more concentrated were the fibres in the concrete matrix, hence the faster the heat transferred from the conductive fillers to the concrete surface; in fact, after 60 seconds of induced heating, b1fcon 2 reached an average temperature of $82.7^{\circ} \mathrm{C}$, while b2fcon 2 and b3fcon 2 showed temperatures of $116.2^{\circ} \mathrm{C}$ and $118.9^{\circ} \mathrm{C}$, respectively. Notwithstanding, a modest increment in the heating speed could be observed from $1.5 \%$ of fibres to $2.0 \%$ which could be explained by the worsening of the distribution of fibres as a consequence of the aggravated workability when the volume percentage of fibres increases.

\subsection{Crack filling inspection}

In Figure 8, the analysis of the assembled images of the four sections of one specimen from b1fcon 2 is shown. The red closed polyline delimits the longitudinal area of the crack in each section while the blue-filled area within it represents the bitumen filling.

Both the total area of the crack and the portion of it filled with bitumen were calculated for each section. In order to calculate the healing efficiency of the entire specimen the assumption of constant bitumen filling along the thickness of each section was taken.

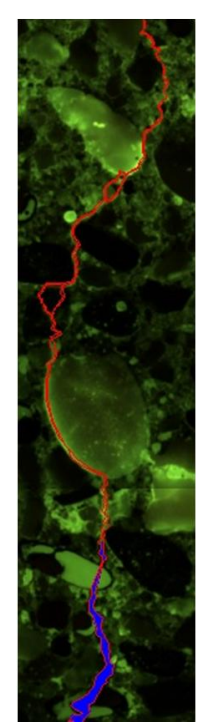

1

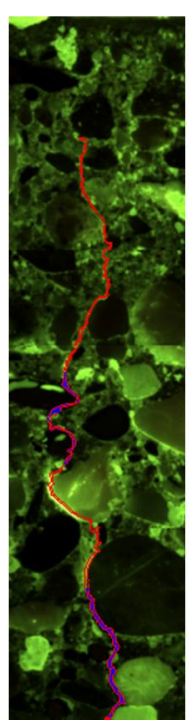

2

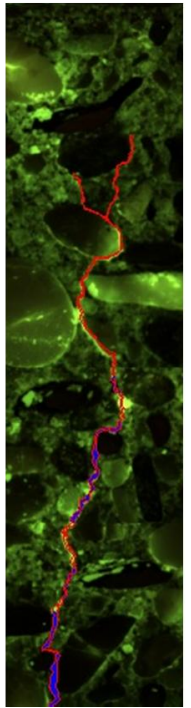

3

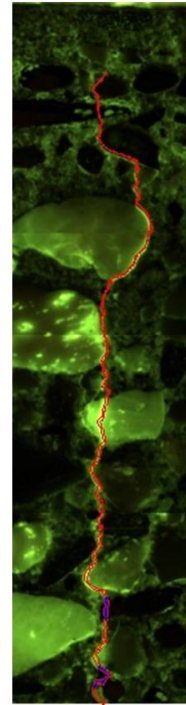

4
Figure 8: Image analysis of one specimen.

The histogram in Figure 9 shows the average Crack Filling Efficiency (C.F.E.) for b1fcon2, b2fcon 2 and b3fcon2.

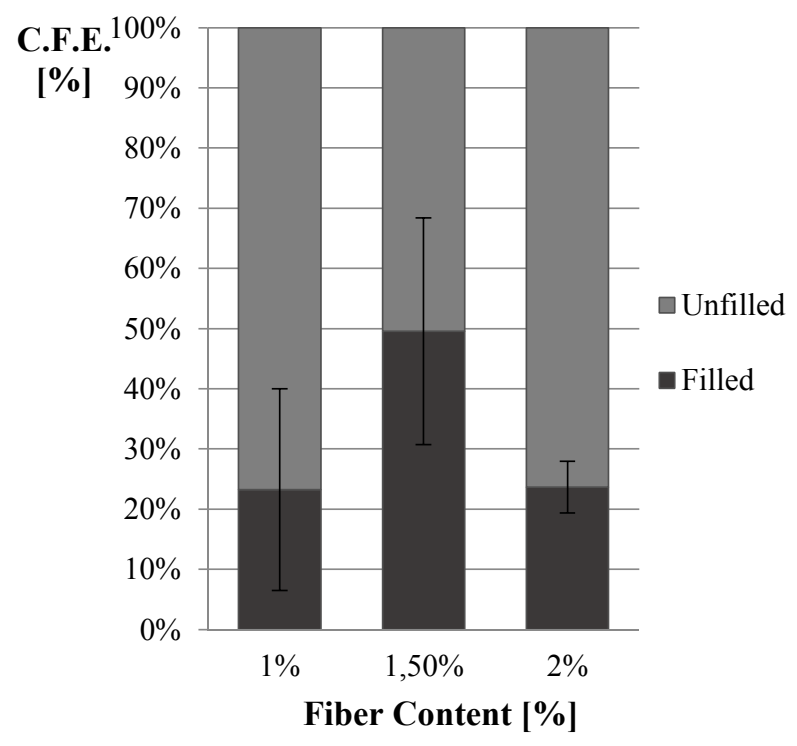

Figure 9: Average C.F.E. for b1fcon2, b2fcon2 and b3fcon2, corresponding to a fiber content of $1.0 \%$, $1.5 \%$ and $2.0 \%$, respectively.

Bitumen filling the crack occupied a $23 \%$ to $49.7 \%$ of the total area of the crack. The healed portion of the crack was approximately contained within the inferior half part of the specimen, located nearer to the coil. This is due to both the existence of higher temperatures and the larger width of the crack near to the coil. In farer zones the combination of high viscosity of bitumen due to a lower heating temperature and 
tightness of the crack, inhibited the healing mechanism.

On the other hand, an increment on the crack filling percentage of almost a $50 \%$ occurred when fibres amount was increased from $1.0 \%$ to $1.5 \%$. In fact, fibres are randomly distributed in the concrete element and so the crack will be bridged by an increasing amount of fibres by increasing the fibre content, which implies a higher amount of bitumen flowing towards the crack. In spite of this, a decrease of the C.F.E. was obtained by further increasing the amount of fibres from $1.5 \%$ to $2.0 \%$ coherently with what was found in 4.1. regarding the distribution of fibres.

\subsection{Water leakage rates}

The most important feature of the material would be the healing effect in terms of decrease in permeability due to the impervious nature of bitumen.

Results of the permeability test are summarized in Table 2.

\begin{tabular}{c|c|c|c|c}
\hline \multirow{2}{*}{$\begin{array}{c}\text { Mix } \\
\text { design }\end{array}$} & \multicolumn{2}{|c|}{$\begin{array}{c}\text { Leakage rates } \\
{[\mathbf{m g} / \mathbf{s}]}\end{array}$} & \multicolumn{2}{c}{$\begin{array}{c}\text { Healing Efficiency } \\
{[\%]}\end{array}$} \\
\cline { 2 - 5 } & Unhealed & Healed & Ave. & St. Dev. \\
\hline b1fcon2 & 67,7 & 27,8 & 65,5 & 19,1 \\
\hline b2fcon2 & 62,6 & 20,4 & 78,5 & 2,1 \\
\hline b3fcon2 & 117,2 & 38,9 & 70 & 14,9 \\
\hline
\end{tabular}

Table 2: Permeability test results.

Before healing occurred, the leakage rates of water going out through the crack were very similar between the mixtures containing $1.0 \%$ and $1.5 \%$ of fibres, with a slight diminution from b1fcon2 to b2fcon2. FRC is thought to reduce the overall crack width when fibres bridge the crack thus by increasing their amount one should expect to obtain a decreased permeability rate. The permeability rate for the specimens with $2.0 \%$ of fibres was found to be almost twice higher instead.

The improvement on the water tightness of the crack ranged from $65 \%$ to $78 \%$ after healing. A similar trend to that explained in 4.1 and 4.2 was found for the healing efficiency rates of b1fcon2, b2fcon2 and b3fcon2.

\subsection{Mechanical behaviour after healing}

The migration of bitumen from the coating of the fibres to the crack leaves a cavity around the fibre and therefore the bond characteristics between fibres and concrete matrix change. Since the shape of the fibres resulting from the hand chopping cannot be defined as totally hooked-ended it is difficult to separate the influence of shape and debonding on the mechanical behaviour of the specimens after healing. Consequently, the recovery of the mechanical properties wasn't hereby investigated. Nevertheless, the mechanical behaviour of healed specimens was compared to that of unhealed specimens. Figure 10 shows the Load vs. COD curve of an unhealed specimen in a) and of a healed specimen in b) during a 3Point bending test.

a)

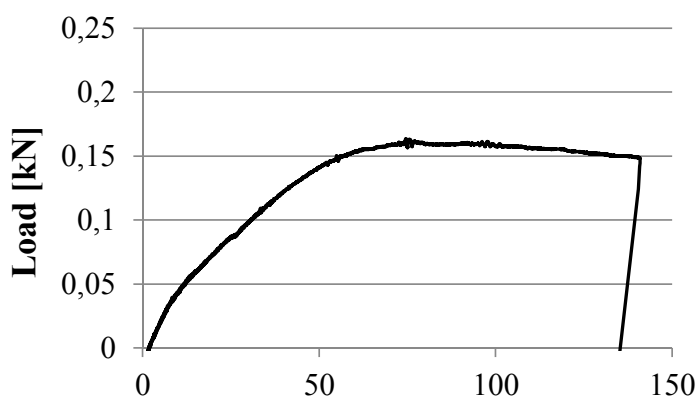

b)

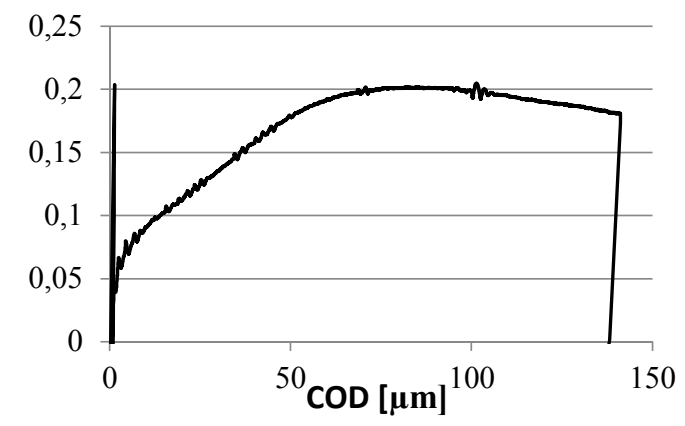

Figure 10: Load vs. COD for a)unhealed specimen, b)healed specimen.

The presence of an initial elastic branch was observed in the case of healed beams. This characteristic behaviour can be attributed to the elastic deformation of the layer of bitumen within the crack surfaces. The failure of the bitumen layer occurs for the chosen rate of displacement and afterwards the load is taken by the ligament and the slip of the fibres bridging the crack. Figure 11 shows the symmetry of the 
bitumen footprints on two pairs of crack surfaces; hence the failure is likely to occur within the bitumen layer instead of at the concrete-bitumen interface.

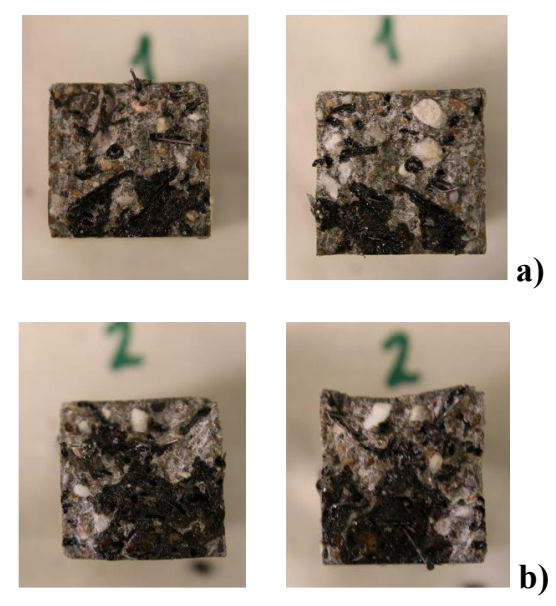

Figure 11: Symmetry of the bitumen layer fracture.

The area of bitumen observed on the crack surfaces was also found to be proportional to the entity of the initial branch maximum load for each specimen. Still, the thickness of the bitumen layer wasn't taken into account to throw such conclusion, thus some reservations should be kept. The average initial branch maximum loads for each fibre content is shown in the bar graph in Figure 12.

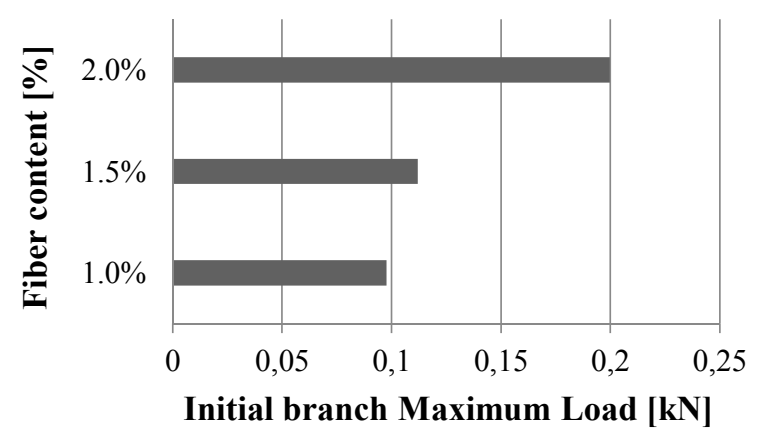

Figure 12: Initial branch maximum load for b1fcon1, b2fcon2 and b3fcon2.

\section{CONCLUSIONS}

Results show that by using bitumen-coated steel fibre reinforced concrete and induction energy, cracks $160 \mu \mathrm{m}$ wide can be partially sealed, producing improvement to the water tightness of concrete.Besides, it was found that the healing mechanism was highly influenced by the distribution of the fibers inside the element; specifically a uniform distribution of the fibers guaranteed the presence of fibers and healing agent bridging the crack.

Moreover, the distribution of temperature on the concrete surface and the corresponding heating speed were directly linked to the distribution of fibers and thus to the prediction of the healing efficiency. In the same way, the suitability of fluorescent microscopy and 3Point bending test of healed specimens to quantify healing was demonstrated.

This study was performed to show the potential of the method for healing cracks in this way. Further optimization as discussed below should be done to create a perfect self-healing technique.

\section{RECOMMENDATIONS}

The work presented in this paper represents one part of a more exhaustive research in the topic. Mechanical properties of the material will be deeply analysed and optimized in the near future. In addition, further optimization should be studied regarding the amount, shape and dimensions of the fibres and the penetration class of bitumen.

\section{ACKNOWLEDGEMENTS}

The technical support of Mr. Arjan Thijssen, Mr. Marco Poot, Mr. Maiko van Leeuwen and Mr. Jan Willem Bientjes are highly acknowledged. The assistance of Msc. Damian Palin is also appreciated.

\section{REFERENCES}

[1] The concrete conundrum. Chemistry world; March 2008 pp. 62-63.

[2] Carpinteri A., Ingraffea A.R. (eds). (1984) Fracture mechanics of concrete: material characterization and testing. Martinus Nijhoff Publishers, XII +202 pages, The Hague Boston Lancaster.

[3] Yunovich, M., Thompson, N.G. (2003) Corrosion of highway bridges: Economic impact and control methodologies. Concrete Int., Vol. 25, 1, pp. 52-57

[4] Freyermuth, C.L. (2001) Life-cycle cost analysis for large segmental bridges. 
Concrete Int., Vol. 23, 2, pp. 89-95.

[5] Liu Q. et al. (2010) Induction heating of electrically conductive porous asphalt concrete. Constr. Build Master.

[6] EN 1766:2000 Products and systems for the protection and repair of concrete structures - Test methods - Reference concretes for testing.

[7] Richard E. Haimbaugh. (2001) Practical Induction Heat Treating. ASM International, pp. 5-18. 